This is a pre-publication author draft. The paper will appear in the fall 2017 issue of ISLE: Interdisciplinary Studies in Literature and Environment

Speciesism Party: a vegan critique of Sausage Party

Matthew Cole and Kate Stewart

Scholarly Article—vegan studies cluster 
This is a pre-publication author draft. The paper will appear in the fall 2017 issue of ISLE: Interdisciplinary Studies in Literature and Environment

\section{Speciesism Party: a vegan critique of Sausage Party}

This paper provides a critical vegan reading of the comedy animation film Sausage Party (2016), directed by Conrad Vernon and Greg Tiernan and starring Seth Rogen and Kristen Wiig. Such a reading is situated within an emerging vegan studies framework (Wright 2015) that is sensitive to the reproduction of unequal power relations between humans and other species, but also how those power inequalities intersect with intra-human power relations along the lines of gender, sexuality, "race," age, class, different experiences of embodiment and so on. Sociologist Erika Cudworth argues that "[w]e need as full an analysis of social intersectionality as we are capable of," so that the critical focus remains on "relational systems of power" (Cudworth 2015, 101). Cudworth (2011) also introduced the concept of anthroparchy, to signify the human domination of nature, with "nature" including but not limited to other animals. In that context, Sausage Party perpetuates anthroparchy, in so far as it normalizes the consumption of "animal products" for the audience. Those consumption practices are dependent on systems of production that are implicated in major environmental crises (Twine 2010), including mass extinctions, climate change, deforestation, water pollution and water scarcity, which might be summed up by Michael Fox's (2000) term "ecocide." Cudworth (2014) argues that a relational system of power comprises both ideas and beliefs as well as contextually embedded social practices. In this paper, we argue that Sausage Party provides an exemplary case study in the cultural reproduction of such an intersected relational system of power. It celebrates ecocidal, oppressive consumption practices at the same time as it reproduces ideas and beliefs, or social norms, of unequal relations between species, between genders, between the differently abled, and so on. This may be made clearer by situating the critique of Sausage Party in the context of recent research that may be broadly construed as operating within a vegan studies framework.

\section{Sausage Party in the context of vegan studies}


This is a pre-publication author draft. The paper will appear in the fall 2017 issue of ISLE: Interdisciplinary Studies in Literature and Environment

A broad strand of critical vegan readings of popular culture has proliferated in recent years. These have targeted, for instance, animal product advertising (Cole and Stewart 2018; Cole 2017; Linné and Pedersen 2016; Stănescu 2016; Fitzgerald and Taylor 2014; Cudworth 2011; Adams 2004a), Hollywood representations of both real and animated nonhuman animals (Malamud 2016; Loy 2016; Molloy 2011; Stewart and Cole 2009; Baker 2001), print media (Freeman 2016; Cole and Stewart 2014), online games (Cole and Stewart 2017), television shows (Cole and Stewart 2016; Cudworth and Jensen 2016; Wright 2015) and social media (Linné 2016). Although inflected with the particular concerns of their authors and by the disparate cultural forms under analysis, this body of work shares a common theme of problematizing representations of nonhuman animals and of consumption practices that denigrate nonhuman "others" compared with "us." The authors thereby also implicitly or explicitly point towards alternative, post-exploitative ways of relating across species. Insofar as popular culture reproduces oppressive relational systems of power, it remains an obstacle to the social realization of those alternatives, and for this reason vegan cultural critique has an important part to play within a wider vegan social movement that opposes oppressive power relations in all their manifestations). ${ }^{1}$

Sausage Party situates anthropomorphised food items (and other commodities) as heroic outsiders struggling against seemingly invincible opposition (in this case their human consumers) in a narrative that is structurally familiar from the predicament of numerous animated nonhuman animal protagonists, like those in The Lion King (1994), Chicken Run (2000), or Shaun the Sheep (2015). In previous work (Cole and Stewart 2014; Stewart and Cole 2014) we have critiqued these and similar films for their reproduction of speciesist norms that legitimate the consumption of other animals, while simultaneously marginalizing an ethical vegan alternative to human violence. A key aspect of this process is their use of what Carol J. Adams has termed the "absent referent" (Adams 2004b). The absent referent facilitates the separation of real nonhuman animals from their commodification as "animal products" and from their human consumers. In the case of the aforementioned films, the absent referent functions by making the fates of real exploited nonhuman animals invisible, 
This is a pre-publication author draft. The paper will appear in the fall 2017 issue of ISLE: Interdisciplinary Studies in Literature and Environment

through the distraction of anthropomorphised animal "characters," such as Simba the lion king, or the eponymous Shaun the sheep. These characters act as lightning rods for the empathy of audiences (Stewart and Cole 2009), inhibiting recognition and critique of a prevailing speciesist order. Such films in turn form part of a broader process of cultural socialization, which normalize and legitimate the human domination of other animals at the same time as obscuring the massive scale and intensity of violence and suffering that underpins that domination, in slaughterhouses, vivisection laboratories, "farms" and all places of confinement and execution to which humans consign nonhuman animals (Cole and Stewart 2014).

Sausage Party differs from these films by targeting an adult audience, by being a purely comic film without the drama and pathos of The Lion King et al., and by anthropomorphising products made from the bodies of nonhuman animals rather than nonhuman animals themselves. Sausage Party does not have to accomplish the speciesist cultural labour of conceptually separating loved nonhuman characters from real nonhuman victims, given that this has already been thoroughly embedded through the childhood socialization process (Cole and Stewart 2014). As such, Sausage Party is able to inhabit the comedy genre, because unequal species relationships are tacitly assumed to have been accepted and normalized among the film's audience. As Weaver's work illustrates in the context of racist comedy, humor is a powerful discursive tactic for deflecting ethical critique (Weaver, 2011). In the context of a critique of gender humor, Abedinifard invokes “Billig's insight, that ridicule functions as a universal disciplinary tool for maintaining the social order" (2016: 238). Vegan critique therefore needs to engage with the serious implications of comedy that relates to nonhuman animals. Ironically, the invisibility of nonhuman animals is almost total, both literally in terms of a lack of on-screen presence, and discursively as doubly absent referents in Sausage Party, but the comedy depends on that invisibility. In the next section of the paper, we outline the commercial success of Sausage Party and provide a brief synopsis, before turning to consider how it "humorously" articulates oppressive power relations in detail. 
This is a pre-publication author draft. The paper will appear in the fall 2017 issue of ISLE: Interdisciplinary Studies in Literature and Environment

\section{Sausage Party: success and synopsis}

Sausage Party (2016) is a CGI (Computer Generated Imagery) animation comedy film aimed at adults, being awarded an R for Restricted rating by the MPAA (Motion Picture Association of America) in the USA and an 18 certificate by the BBFC (British Board of Film Classification) in the UK. The film proved to be very profitable, grossing $\$ 97,670,358$ in the USA and $\$ 140,539,785$ worldwide at the box office, for a production budget of $\$ 19,000,000$ ("Sausage Party"). The film peaked at number 2 at the USA box office in its first week of release ("Sausage Party"). Thematically, Sausage Party is a parody of the trend in the last two decades or so for CGI animation movies targeting children, that anthropomorphize inanimate objects, such as Toy Story (1995) and its sequels. The film's action is primarily located in a fictional supermarket, "Shopwell's," in which food and other commodities are sentient characters, believing that human shoppers are gods. In a song ("The Great Beyond") that opens the film, the products fervently hope that the gods will buy them and deliver them to a "promised land," where "we will live our dreams together." The humans/gods are oblivious to the sentience of the commodities, unless under the influence of drugs, a pivotal plot point later in the film that we discuss below. A returned food item (Honey Mustard) reveals the shocking truth that humans kill and consume the inhabitants of Shopwell's, but most of the commodities refuse to believe him, holding fast to their faith in The Great Beyond. The rest of the film centers on protagonist Frank, a personified hotdog voiced by white Canadian actor Seth Rogen, and his quest to convince the other residents of Shopwell's to relinquish their naïve faith and resist their human oppressors. The quest is hampered by an antagonist character in the form of a vaginal douche (voiced by white American actor Nick Kroll) who seeks revenge on Frank for thwarting his being purchased and taken to The Great Beyond. Frank is driven as much by a desire to woo Brenda, a "Glamor Bun" (voiced by white American actor Kristen Wiig), as he is by a wish to dispel the myth of The Great Beyond in general. 
This is a pre-publication author draft. The paper will appear in the fall 2017 issue of ISLE: Interdisciplinary Studies in Literature and Environment

The film literally climaxes with a successful battle waged against the shoppers and Shopwell's staff, followed by an orgy between the film's commodity-characters. A coda reveals the artificiality of the filmic universe to the main characters, as the narrative comes up against the impossibility of commodity-liberation without implying the starvation of Shopwell's human consumers, and of human consumers in general. This last point is crucial, as it universalizes fictional sentience to all commodities, but equally universalizes the deprivation of sentience by the film-makers at the end of the film when the commoditycharacters are "revealed" as fictional. This human capacity to grant or withhold subjectivity to nonhuman "characters" is central to the objectification of nonhuman animals in Sausage Party, which we explore in the next section.

\section{Objectifying nonhuman animals}

Sausage Party firstly uses familiar techniques to reproduce the structure of the absent referent: the killing of nonhuman animals and the oppressive practices of confinement that are intrinsic to the manufacture of "animal products" are not depicted or alluded to in the film. This is reflected in the lopsided mythology of The Great Beyond-the afterlife myth has no genesis counterpart in Sausage Party. The commodities appear on the shelves as fully mature - young adults in the case of the central pairing of Frank and Brenda. None of the commodity-characters express curiosity about where they came from, who their ancestors might be, and so on. There is almost nothing in the imagery or script of the film that explicitly connects Frank and his hotdog friends with the real pigs or cows killed to produce the commodities which they represent. Exceptionally in the film credits, an image of one hotdog character, Carl, is backed with a drawing of a pig, while another, Frank, is superimposed over an ingredients list including "beef stock" as well as "lips and assholes," but this comic aside (only noticeable by freeze-framing the film) itself displaces contemplation of genuine engagement with the reality of nonhuman animal slaughter. It is therefore striking that a coyness about the killing of nonhuman animals is shared between the adult-orientated Sausage Party and the children's films that it recalls in many ways: for 
This is a pre-publication author draft. The paper will appear in the fall 2017 issue of ISLE: Interdisciplinary Studies in Literature and Environment

instance, although The Lion King and Puss in Boots (2011) feature carnivorous animals as their heroic protagonists, both films manage to keep depictions or discussions of predation offscreen and away from the consciousness of audiences (Cole and Stewart 2014; Stewart and Cole 2009). Affective responses to Sausage Party or cognate children's films, whether of amusement or sentimentality respectively, remain untroubled by allusions to real-world speciesist violence. The adult affective tone of Sausage Party is also, however, evidenced by horror-style shocks that centre on violence against animal products, rather than nonhuman animals themselves.

Secondly, it is telling that the personified commodities in Sausage Party are largely restricted either to heavily processed animal products, such as hotdogs, or to commodities in which "animal products" are not present (such as fresh produce), or at least are not conspicuously present (such as alcoholic beverages). That is, products that are more easily associated with killed nonhuman animals are not granted subjectivity, are not resurrected and given a fictional afterlife in the film. Although the narrative takes the characters through an odyssey through many of Shopwell's aisles, it avoids the "meat" aisle, so that packaged body parts from cows, pigs, chickens and so on are not shown on screen. The chief exception is the on-screen appearance of dead fishes and crustaceans on ice in a "Fish and Seafood" display. This appears very briefly during the opening "Great Beyond" song sequence, and later as Frank approaches the utensil aisle (called "the dark aisle" in the film), with its menacing knives that presage his discovery of a cookbook that confirms the truth of humans as commodity-killers, rather than saviours. The dead fishes have a cartoon-like appearance, with over-sized eyes and pouting lips, but lack the expressive faces of the animated commodity-characters in the film, while the crustaceans' bodies are arranged almost architecturally in a dream/song-sequence in which Frank yearns for Brenda during his journey to the "dark aisle." They remain firmly as a backdrop to the action and have the distinction of being the only voiceless commodities in the film; Sausage Party singles fishes and crustaceans out to be silenced. 
This is a pre-publication author draft. The paper will appear in the fall 2017 issue of ISLE: Interdisciplinary Studies in Literature and Environment

As Smith (2002) highlights, the effective silencing of nonhuman animals through the cultural denial of their experiences of slaughter is a key component of their subjugation. Slaughter is not only unseen, but unheard. Arguably, the greater species-otherness of fishes or crustaceans compared with land mammals such as cows, or birds such as chickens, makes them a less risky option for depiction, in terms of maintaining the absent referent in the film. A more fleeting exception is the title of a cookbook alongside the one Frank opens ("Beyond Great Cooking"—a pun on "The Great Beyond" salvation song), entitled "Insect Protein." This alludes to recent discussions about the potential for extending the use of insects for human food (for instance see "UN urges people to eat insects to fight world hunger"), in part as a solution to the crisis of "livestock" production, not least in relation to ameliorating environmental pressures associated with the "livestock" industry, such as climate change (Twine 2010). As such the book title subtly incorporates insect species as imagined future absent referents in Western food cultures (albeit it should be recognized that commodified insects are already consumed in vast numbers by Western consumers, for instance scale insects killed to produce cochineal food colouring or shellac beetles killed to produce wax used to coat fruit).

Thirdly, the structure of the absent referent is doubled through the subjectivity granted to "animal products" rather than nonhuman animals themselves. That is, a sequence of transformations takes place off and on screen: firstly, real nonhuman animals are killed, and thereby subjects become objects (someone becomes something as Carol Adams famously described it (2004b)). Secondly, real "animal products" are re-subjectified as characters in Sausage Party. Thirdly, those characters are threatened with re-objectification by human consumers. This is dramatized in several scenes in the film. For instance, when Frank enters the "dark aisle" of kitchen equipment, bladed implements are tinted red as if already bloodied, and as if Frank, as an exsanguinated commodity, could still bleed by implication. Knives fall from their hangers and narrowly miss piercing and killing him. The function of real knives in the slaughterhouse, to exsanguinate pigs, is therefore also made absent by the film. The "Beyond Great Cooking" book contains images of a burger with an 
This is a pre-publication author draft. The paper will appear in the fall 2017 issue of ISLE: Interdisciplinary Studies in Literature and Environment

eye displaced from its socket, being eaten by an elderly white man while still-living burgers (i.e. exhibiting anthropomorphic expressions of pain) are cooked on a barbecue; a "dead" steak shown open mouthed (but eyeless), which a white man pierces with a fork; a "chicken drumstick" reaches out with an arm while being bitten by a young white woman. The horror culminates as Frank turns the page to reveal an image of a hotdog in a bun being bitten into by a middle-aged white woman, with "blood" / ketchup splattering from the wound. In a preceding scene, Frank's hotdog friend Barry (voiced by white Canadian actor Michael Cera) becomes visible to a human drug-user under the influence of "bath salts" (slang for a synthetic narcotic). On realizing his visibility, Barry pleads, "please don't kill me," and in response the drug-user says, "the bath salts are showing me the real world. It's fucking lifted the veil of non-reality." This exchange comically depicts a hallucinogenic unveiling of the oppression inherent to fictive ("non-reality") human-commodity relations, but thereby makes a sober recognition of the real-world absent referent seem ridiculous by implication.

Fourthly, Sausage Party compounds the absent referent by tacitly asserting the enhanced subjectivity of post-mortem characters such as Frank and Barry. As Davis argues, the human appeasement of conscience over killing (humans or nonhumans) depends upon assertions that the victim either, “doesn't feel, doesn't know, doesn't care, is complicit, or isn't even there. In the latter case the victim is configured as an illusion" (2011: 45; emphases in original). That is, the drug-user is only able to perceive the sentience of Barry as resubjectified anthropomorphic character, not the sentience of the pig or pigs killed to "produce" him. Later in the same scene, a slice of pizza crawls towards the drug-user crying out that, "You ate my goddam legs." The pizza trails tomato sauce as if it were blood but also is covered with cheese and slices of pepperoni. The drug-user's reply is "I've committed pizza genocide." The oppressed cows and pigs are invisible, even under the revelatory influence of "bath salts." The real nonhuman animals are rendered illusory, because as Davis argues, "Our use [in this case of 'animal products'] becomes their ontology" (2011: 45; emphasis in original). Of course, to do otherwise would make Sausage Party a radically 
This is a pre-publication author draft. The paper will appear in the fall 2017 issue of ISLE: Interdisciplinary Studies in Literature and Environment

different kind of film, but we spell this out here to demonstrate how producers of popular culture make particular choices with regard to revealing, or more likely concealing, realworld speciesist oppression. After the effect of the drug wears off, Barry is nearly boiled "alive" by the drug-user, reinforcing that the reversal of the fictive absent referent is impermanent and not analogous to a real-world vegan conversion. Within conventional speciesist cultural frameworks, billions of nonhuman animals achieve their telos postmortem as they are consumed, such that it is their sustenance of human subjectivity through ingestion that facilitates a ghostly meta-subjectivity for nonhuman animals (see Davis 2011). Sausage Party is distinctive for making that paradoxical process culturally explicit, in the ways that it variously withholds subjectivity from nonhuman animals while selectively granting it to "animal products." The quality of that granted subjectivity, however, varies according to the anthropomorphic attributes of the film's characters, which we explore in the next section of the paper.

\section{Intersecting oppressions in Sausage Party}

\section{Gender and heteronormativity}

The objectification of nonhuman animals is largely represented in Sausage Party through its depiction of "animal products," but human objectification is also represented, notably with regard to gender. The sequence of subject-object-subject transformations described above is uneven depending on the gender of the characters. For the hotdogs like Frank or Barry, they invisibilize the objectification of real world animals, and their own subjectivity as characters is threatened, but ultimately not destroyed, by their antagonists in the film. On the other hand, female characters tend to be products that do not necessarily depend in the nonfictional world outside the film, on the oppression of nonhuman animals (though they might, depending on the product formulation). For instance, the two most prominent female characters are Brenda the "glamour bun" and Teresa del Taco, and both are based on baked plant-based products. Both are also sexualized representations. For example, Brenda is curved to simultaneously recall a vulva as well as breasts and buttocks, and her red- 
This is a pre-publication author draft. The paper will appear in the fall 2017 issue of ISLE: Interdisciplinary Studies in Literature and Environment

lipsticked lips have a dual symbolic function as labia to be penetrated by Frank, and lips of the mouth when Brenda speaks. To a limited extent, this sexualised representational style is shared with the hotdogs, obvious phallic symbols, but the reductiveness of the latter symbol means that male viewers evade the totality of bodily scrutiny that female viewers are reminded of by the characters of Brenda and Teresa. This is reinforced by the taboo on displaying male genitalia in popular culture, so that in the film jokes alluding to penis size and sexual performance have a different function to the normalization of a particular "sexy" women's body type. So in sum, the parallel gendered sequence of subjectificationobjectification works thus:

Male "meat" products: subjects (real-world absent referent) become objects (real-world "animal products") become gendered subjects (characters like Frank) risk becoming objects ("killed" characters).

Female "plant" products: objects (non-sentient real-world ingredients) become gendered subjects (characters like Brenda) become objects (reduced to anthropomorphized fetishized women's body parts) risk becoming objects ("killed" characters).

So, while both male and female characters risk ultimate objectification through consumption by humans, that objectification is the least objectionable in the film, as it is entirely fictional—a conjured absent referent to satisfy the plot. But the prior objectification inflicted on the female characters echoes a very real process of objectification that occurs outside the world of the film.

The gendering of the commodities also reinforces the intersection of species and gender hierarchies, given the enduring Western cultural tendency to associate "meat" with masculinity, and concomitantly plant foods with femininity (Fiddes 1991; Adams 2004b). This is tragically ironic given that the real-world pigs killed to "produce" the hotdog counterparts of Frank, Barry et al. are likely to have been female. The irony echoes real life in this respect, in that the augmentation of masculinity associated with the consumption of nonhuman animals' flesh likewise depends to a large extent on the consumption of females' bodies. As Carol Adams has examined in detail, there are close cultural connections between 
This is a pre-publication author draft. The paper will appear in the fall 2017 issue of ISLE: Interdisciplinary Studies in Literature and Environment

the feminized sexualisation of "animal products," especially "meat," and the representation of women's bodies as consumable "meat" in the USA and Western culture more generally (2004a; 2004b).

The physical/sexual scrutiny of female characters is compounded by the moral policing of the behaviour of female characters by male characters in Sausage Party. Most persistently, Brenda is targeted, for instance by Frank for her irrationality. He tells her that it is "hard to have a rational conversation" with her, given her commitment to her faith in The Great Beyond and the ultimate beneficence of humans. By contrast, Frank seeks "the truth." This exchange reproduces patriarchal binary thought (Cixous 1976), the association of women with a series of negatively valued traits (such as irrationality) in opposition to positively valued traits associated with men (such as rationality). This conventional pattern of gender relations is reproduced near the end of the film, when Frank heroically risks his own safety by flying to damsel-in-distress Brenda's aid on a balloon. When Frank is in turn attacked by a human woman, Brenda's response is one of possessiveness and jealousy: "stay away from my sausage," implying female competition for Frank's virility. This encounter and the construction of Brenda's irrationality illustrates the conventionally heteronormative narrative of Frank and Brenda's unfolding relationship, in which Frank unequivocally pursues, woos and finally "wins" Brenda.

Heteronormativity is a concept developed from Rich's (1980) concept of "compulsory heterosexuality," which asserts that women are not only normally but inevitably and necessarily drawn to men, for economic protection, adult sexuality, and psychological completion, where the heterosexually constituted family is the basic social unit. Early in the film, Frank punningly declares himself to be "a bunogamist" to assert his commitment to Brenda the "glamour bun." By contrast, Brenda doubts herself for being "not pure" once she leaves her "glamour bun" packaging. She is concerned about her own sexual propriety, and about being punished by the gods for "touching tips" (an allusion to a fleeting eroticized incident of Brenda and Frank touching each other's cartoon hands). Such concerns are not exhibited by the male characters, especially Frank, in the film, not least because Frank's 
This is a pre-publication author draft. The paper will appear in the fall 2017 issue of ISLE: Interdisciplinary Studies in Literature and Environment

burgeoning rationality liberates him from The Great Beyond myth. Frank's heroism in fact inheres in a mixture of masculine rationality and irrationality. That is, a commitment to discovering empirical evidence (the "truth" revealed by the cookbook) combined with his sexual desire for Brenda. This combination sets Frank apart from the other characters in the film, which can be illuminated with reference to the concept of hegemonic masculinity. This may be defined as "the pattern of practice (i.e., things done, not just a set of role expectations or an identity) that allowed men's dominance over women to continue." (Connell and Messerschmidt 2005: 832) As an archetypal white American male, Frank's identity and behaviour situate him as an idealized depiction of hegemonic masculinity.

\section{Ethnic stereotyping in Sausage Party}

Gender inequality and heteronormativity are also intermingled with ethnic stereotyping in Sausage Party, which in turn reproduce ethnic hierarchies in the film, despite moments of subversion that in themselves tend to be undercut by problematic reassertions of hegemonic masculinity. Frank stands at the pinnacle of the hierarchy. His whiteness is unmarked and unremarked in the film, a defining characteristic of privileged identities, and he shares this ethnic identity with the other hotdogs in his package, notably the key characters of Barry (already mentioned above) and Carl (voiced by Jewish-American actor Jonah Hill). The white American males then, are also the "meatiest," most virile and most heroic characters in the film. To emphasise the point, in the credits, the hotdog character Carl appears on mock-packaging bearing the slogan "100\% NOT VEGETARIAN." Although Frank is the central hero, Barry plays a sub heroic part, by surviving being taken out of Shopwell's and the encounter with the drug-user, finally returning with the drug-user's accidentally severed head ${ }^{2}$ to support Frank's insurrection. On the other hand, the chief antagonists in the film are also white males: the douche is implicitly a white American male, as is the shop assistant who the douche eventually possesses in his attempt to effect his revenge and the drug user who almost kills Barry. Other ethnicities tend to play more minor roles. The only major female character besides Brenda is the implicitly Mexican Teresa del 
This is a pre-publication author draft. The paper will appear in the fall 2017 issue of ISLE: Interdisciplinary Studies in Literature and Environment

Taco (voiced by Mexican-American actor Salma Hayek). Teresa is a lesbian character who also amorously pursues Brenda. Brenda then is the most sexually desirable character in the movie, a desirability shared with other "glamor buns" in her package. Brenda's sexual attraction is emphasized in the credits sequence, in which the character is depicted with the slogan, "the softest bun for your meat." Her whiteness is literally depicted through her being made from white bread. Meanwhile, Teresa's subordinate status in the romantic hierarchy is effected through losing out in the romantic stakes to Frank, although she requites her desire for Brenda in the film's literally climactic orgy scene.

Teresa's ethnic identity is effected partly through her accent and partly through her status as a commodity associated with a specific ethnic food culture. Likewise, other Mexican characters in Sausage Party include a bottle of tequila and El Guaco, a guacamole gangster. Kareem Abdul Lavash is a Middle Eastern character (voiced by a Jewish-American actor, David Krumholz), part of the motley crew of commodities joining together under Frank's leadership to resist the human "gods" in the film. Like Frank, Lavash also subjects Brenda to moral scrutiny but simultaneously asserts Frank's legitimate patriarchal control of her. At one point, he upbraids Brenda for her "loose morals" and at another he tells Frank to “control your insolent bun." Sausage Party therefore reproduces patriarchal gender relations in the context of white privilege, while singling out a Middle Eastern character for the most conspicuous assertion of patriarchy: Patriarchy is disowned by the dominant white culture by giving these lines to Lavash, and thereby through a racist stereotype of Middle Eastern patriarchy, at the same time as it is more subtly reinforced throughout the film by white characters as described above. Lavash's Jewish-American sparring partner in the film is Sammy Bagel Jr. (voiced by white American actor Edward Norton). Their mutually provocative dialogue is eventually revealed as repressed homosexual desire in the orgy scene. Although the depiction of homosexual sex complicates the reproduction of heteronormativity in the film, it is noteworthy that lavash, bagel, and taco are all baked goods, that is plant foods. Non-normative sexuality is thereby principally associated with ethnic minority characters who lack the "meaty" virility of Frank and his buddies, but share 
This is a pre-publication author draft. The paper will appear in the fall 2017 issue of ISLE: Interdisciplinary Studies in Literature and Environment

the "meatless" constitution of Brenda and her sister glamor buns. However, Lavash's homosexuality is repressed and projected through his moral condemnation of Brenda, while Teresa's sexuality, albeit as a lesbian, is liberated, thereby mapping onto stereotypes of Middle Eastern and Latin American sexual cultures respectively.

Returning to the theme of ethnic stereotyping through food cultures, Sausage Party also includes German sauerkraut stereotyped as punningly fascistic enemies of "juice," an Irish potato, the Black-American Mr. Grits, and the Native American Firewater bottle of liquor. The latter two characters, together with Twink the Twinkie (a US confectionary product) constitute the immortal "non-perishables" who are wise to the myth of the Great Beyond, and enlighten Frank, with the aid of drugs (smoked rather than injected as with the "bath salts"). The ethnic difference between Firewater and Frank is significant given that the hotdogs (branded as "fancy dogs" on their packaging) and the "glamor buns" are displayed in Shopwell's surrounded by red, white and blue paraphernalia to signify US Independence Day. It is this holiday which gives Frank, Brenda and friends confidence that they, above rival commodities, will be chosen for The Great Beyond in the early part of the film. Hotdogs served in white bread buns are therefore highlighted as archetypal US foods, installing white American food culture as the preeminent food culture of the USA, and reinforcing the normalcy of obfuscating the oppression of Native American Nations by white colonists and their descendants (see Nibert 2013). Furthermore, Frank and Brenda's "bunogamous" heterosexual relationship is likewise represented as a central norm of US culture.

\section{Embodiment, and heteronormativity reprised}

The sub-heroic status of Barry is also related to his relative inadequacy as a phallic symbol: Barry is noticeably shorter than the other hotdogs, for which he is ridiculed early in the film: "you deformed nerd." The taunting of Barry compounds ableism and sexism: "I guess now you're weird and a pussy, add that to your list of accomplishments." Wooten (cited in Abedinifard 2016: 236) defines ridicule as, "the act of making fun of some aspect of 
This is a pre-publication author draft. The paper will appear in the fall 2017 issue of ISLE: Interdisciplinary Studies in Literature and Environment

another [that] involves a combination of humor and degradation and encompasses a range of activities like teasing, sarcasm, and ritualized insults." Abedinifard (2016: 240) goes on to argue that, "certain [...] humour-mostly revolving around sexual matters—-targets the disabled as failed gendered subjects." Barry also exhibits emotional sensitivity, which he is advised to repress by fellow hotdog Carl: "just act happy, ignore your feelings." Barry is therefore repeatedly made to feel inferior because of his non-normative embodiment and failure to match up to the performances of hegemonic masculinity by his peer "fancy dogs." Barry's self-doubt is initially exacerbated by the fact that no one chooses him as a sexual partner in the orgy scene, until he meets a similarly neglected "smushed" glamor bun, to whom Barry asks, “you have an abnormality?" The two partner up, but are depicted as only fit for each other. The threat of sexual inadequacy is also deployed by Brenda in the row with Frank in which he berates her for wanting to return home for fear of punishment by the gods. Brenda retorts that "I'll fill myself with something else [...] maybe even an eggplant." The threatened alternative mortifies Frank because of its larger size—Brenda adds, "you'll be amazed what I can fit up there." Frank's humiliation might also be connected to his usurpation by a vegetable, that is a vegan alternative displacing the heteronormative symbol par excellence of "meat."

While a threat to Frank's sexual fulfilment is met with humiliation, it is elsewhere met with sexual violence in Sausage Party. The douche shares with Barry the distinction of being "deformed," thanks to his nozzle becoming bent and his fluid leaking away when falling from the shopping cart of a woman shopper, an event which he blames on Frank. The douche's search for vengeance includes him fellating to death an injured juice carton to replenish his fluid, which he refers back to later in the film: "I sucked a juicy box's dick." However, at the time of the sexual assault, the douche asserts to his victim that, "I'll fuckin' deny it bro." By the time of his admission later in the film, the douche has been driven to the point of insanity by his desire for revenge and no longer cares about vaginal penetration as the fulfilment of his ontology, and instead he anally penetrates the male shop assistant and 
This is a pre-publication author draft. The paper will appear in the fall 2017 issue of ISLE: Interdisciplinary Studies in Literature and Environment

in so doing possesses him as a vehicle for an attack on Frank and friends. He excuses his behaviour with the line, "a hole's a hole bro."

Male homosexual behaviour is therefore enacted as violence perpetrated by a heterosexual character. As Cheng (cited in Abedinifard 2016: 243) argues, “[o]ne way to "prove" hegemonic masculinity is to act aggressively or even violently toward what is regarded as "feminine," for example, women, homosexuals, and nerds." This is also illustrated by Mr. Grits' threat to "fuck the crackers in their cracker asses," as revenge for their invasion of his Shopwell's aisle (an allusion to white colonialism). This threat is fulfilled in the orgy scene. Alternatively, male homosexuality is initially repressed in the case of Lavash and Bagel Jr., or is depicted as transgressive desperation on the part of heterosexual characters. The latter is evidenced by Firewater's aside about being "fuck-aguy baked," implying intoxication as a prerequisite to male homosexual activity. The film also reproduces homophobic stereotyping in the final battle, when a macho monkey nut asserts, "I ain't fighting alongside a bunch of fruits," which is met by a camp limp-wristed gesture from a melon. Shortly afterwards, fruit joins the attack to the tune of "Wake Me Up Before You Go-Go" by Wham! the band famously fronted by George Michael, an iconic, celebrated and now mourned gay figure in popular culture.

\section{Towards a subversive reading of Sausage Party}

The discussion so far has highlighted the reproduction of oppressive power relations, but an opportunity presented by a vegan reading of the film is to highlight the potential for subverting the more overt meanings of Sausage Party. The irony of Brenda taunting Frank with the prospect of a vegan sexual (Potts and Parry 2010) preference for an eggplant was discussed above. Another possibility is to transpose the religious aspects of the narrative, concerning faith, doubt and empirical evidence, into an expose of the naiveté of the shared belief in "meat culture." This can operate on two levels simultaneously: firstly, in relation to vegans speaking truth to power, secondly in relation to imaginatively restoring the absent referents, so that the "animal product" characters become nonhuman animals. 
This is a pre-publication author draft. The paper will appear in the fall 2017 issue of ISLE: Interdisciplinary Studies in Literature and Environment

In terms of the first level, Frank's urge to proselytise the violent truth of nonhuman animal oppression models an urgent zeal familiar to many vegans:

Frank (to Firewater): If what you're saying is true, I gotta tell everyone Firewater: Very noble little sausage. But also very pointless. No one will believe you.

Frank: I have to try. Everyone will die otherwise Firewater: Oh, yeah. That's a good point. Fuck me, right?

On the second level, the exchange would still work if we imagined Frank voicing the perspective of the animals killed to "produce" his sausage form, or indeed if Frank were substituted for one of the fishes or crustaceans instead, i.e. as a recognisable unfragmented nonhuman animal.

When Frank asks for convincing proof that he can show to the duped believers in The Great Beyond, Twink warns him that, “Once you see that shit, it'll fuck you up for life." Again, an analogy may be drawn with the vegan experience of bearing witness to violence through watching slaughterhouse footage, a transformative experience that nonetheless fuels a sense of urgency to share that truth with others: After reading the cook book, Frank declares, "They need to know how wrong they all are before it's too late." Likewise, we might imagine analogous nonhuman animal horror at being confronted with the truth of the slaughterhouse-recognition that their own bodies were dismembered in the cookbook images.

Frank's first attempt at direct revelation is met with denial, another familiar experience for vegans:

Frank: "Everything we've been led to believe is a lie. When we get chosen by the gods, they're choosing us for death. Murder. Automatic expiration. The Great Beyond is bullshit."

Two of the responses to this uncomfortable message include:

Frozen Fruitz: "You don't respect anyone else's beliefs"

Sauerkraut: “...you intolerant piece of shit” 
This is a pre-publication author draft. The paper will appear in the fall 2017 issue of ISLE: Interdisciplinary Studies in Literature and Environment

Such reactions map onto the vegan experience of being condemned for "spreading propaganda," or interfering with the cultural primacy of consumer choice, which treats food as a personal habit divorced from social or environmental consequences (Jenkins and Twine 2014). With a nonhuman animal protagonist, the exchange could be understood as a revelation that the "care" administered by "farmers" was an analogous lie within an animal welfare discourse, which might similarly be met with incredulity by duped farmed animals. In face of such denial, and the seemingly implacable power of the animal-industrial complex, ${ }^{3}$ despair and resignation are understandable responses which might be voiced by either a vegan or a nonhuman animal character (or indeed both united within the same character), and such is voiced by Barry after his encounter with the truth of The Great Beyond: “They [the human 'gods'], they feel no remorse. Oh God, oh God! What's the point of even living any more? I might as well just die." But Barry's later triumph over the druguser gives him new hope (in the way that perhaps a real-life nonhuman animal escape, or liberation, might give hope). This enables him to reignite Frank's quest:

Frank: "I tried to warn everyone but they didn't believe me"

Barry: "Or course they didn't. You just called them all a bunch of fucking idiots. You can't just slam their beliefs. You have to show them that there's a better way. You need to inspire them... You need to give them hope." In light of that lesson, Frank's second speech succeeds in rallying Shopwell's other inhabitants: “Look, I'm sorry. I wasn't respectful of your beliefs and I acted like I had all the answers, but I don't. Nobody knows everything." Here we might see a model for more restrained vegan outreach that avoids alienating non-vegans.

This reading disputes the dominant meanings of Sausage Party, and demonstrates the critical capacity of a vegan studies framework for destabilising oppressive power relations. The obfuscation of violence that we have critiqued in the earlier sections of this paper can be usurped by the script itself, with a modest investment of imagination.

\section{Conclusion: Just a Joke?}


This is a pre-publication author draft. The paper will appear in the fall 2017 issue of ISLE: Interdisciplinary Studies in Literature and Environment

In this paper, we have described how Sausage Party reflects and reproduces intersecting oppressive power relations of species, gender, sexuality, ethnicity and different forms of embodiment. Using Carol Adams' foundational vegan studies concept of the absent referent, we have outlined how the film separates nonhuman animals from film's characters and from the audience in four ways: firstly through not referring to the real animals killed to produce "animal products"; secondly through granting subjectivity to "animal products" who are furthest removed in appearance from the body parts of killed nonhuman animals; thirdly by doubling the absent referent by personifying "animal products," and thereby resubjectifying objectified commodities; and finally by constructing the fictional subjectivity of personified commodity-characters are more meaningful than that of the absented real nonhuman animals. We then described how the process of subjectification and objectification is uneven in relation to the gender of the characters in Sausage Party, such that patriarchal norms about the judgement of women's bodies and sexual morals by men are reproduced. Messages about gender are bound up with the hierarchical reproduction of heteronormative relationships and forms of sexuality, which in turn are mapped on to the deployment of ethnic stereotypes within Sausage Party.

Finally, we outlined how the film's comedy trades off ableist norms related to the embodiment of "deformed" commodity-characters. In an extra feature on the Blu-Ray release of the film, Evan Goldberg (co-writer/producer) commented that "There's an old tradition in animated films especially with these CG ones of the secret life of the world of cars and world of toys. And that conversation eventually led us to realise there's a comedic version of it in the secret life of food," while Seth Rogen (voice of Frank and co-creator of the film) added that, "It's a very bizarre take on a hero's journey, but it kind of follows that structure a little more of, like, the outcast in society who has a call to release the masses from their shackles in a way." These comments suggest denial of the experiences of the animated real world subject(s) killed to produce the commodities on who the film's "animal product" based: Real pigs or cows, whose dead bodies are commodified as hotdogs, would benefit far more from a release from their confinement than the fictional masses of personified 
This is a pre-publication author draft. The paper will appear in the fall 2017 issue of ISLE: Interdisciplinary Studies in Literature and Environment

commodities in Sausage Party. Furthermore, the celebration of "meat culture" in Sausage Party sustains the ecocidal momentum of the animal-industrial complex. It is the very absence of environmental themes or concerns from the film that make it important: ecological concerns are culturally marginalized in relation to practices, such as "meat"eating, that are especially environmentally damaging. This kind of analysis is therefore an important step towards refining strategies for critically raising the cultural profile of "meat" as an environmental disaster. Sausage Party is therefore a deeply conservative film, despite its pretensions to comedic subversion of the CGI animation genre through its adult rating, widespread use of swearing, sexual and violent content. That conservatism inheres primarily in the film's joking celebration of oppressive power relations. This analysis has therefore drawn attention to the need for further research integrating vegan and humour studies in order to mutually further the understanding of how oppressive power relations are culturally reproduced.

\section{Works Cited}

Abedinifard, Mostafa. "Ridicule, gender hegemony, and the disciplinary function of mainstream gender humour." Social Semiotics, vol. 26, no. 3, 2016, pp. 234-249. Adams, Carol J. The Pornography of Meat. Continuum, 2004a.

Adams, Carol J. The Sexual Politics of Meat: A Feminist-Vegetarian Critical Theory. 20th Anniversary Edition, Continuum, 2004b.

Baker, Steve. Picturing the Beast: Animals, Identity, and Representation. U of Illinois P, 2001.

Chicken Run. Directed by Peter Lord and Nick Park. Dreamworks, 2000. Film.

Cixous, Hélène. "The Laugh of the Medusa." Signs, vol. 1, no. 4, 1976, pp. 875-893.

Cole, Matthew. "Hiding and Legitimating Oppression in 'Dairy Product' Advertising." Animal Oppression and Capitalism: Volume One: The Oppression of Nonhuman Animals as Sources of Food. Edited by David Nibert. Praeger Press, 2017, pp. 19-33. 
This is a pre-publication author draft. The paper will appear in the fall 2017 issue of ISLE: Interdisciplinary Studies in Literature and Environment

Cole, Matthew and Kate Stewart. Our Children and Other Animals: The Cultural Construction of Human-Animal Interaction in Childhood. Routledge, 2014.

Cole, Matthew and Kate Stewart. "'“I Need Fish Fingers and Custard': The Irruption and Suppression of Vegan Ethics in Doctor Who." Meat Culture. Edited by Annie Potts, Brill Publishing, 2016, pp. 198-221.

Cole, Matthew and Kate Stewart. "'A New Life in the Countryside Awaits': Interactive Lessons in the Rural Utopia in 'Farming' Simulation Games." Discourse: Studies in the Cultural Politics of Education, vol. 38, no. 3, 2017, pp. 402-415.

Cole, Matthew and Kate Stewart. “Advertising Oppression: The Reproduction of Anthroparchy on UK Television." Critical Animal Studies: Towards Trans-species Social Justice. Edited by John Sorenson and Atsuko Matsuoka, Rowman and Littlefield International, forthcoming 2018.

Connell, R. W., and James W. Messerschmidt. "Hegemonic masculinity rethinking the concept." Gender E Society, vol. 19, no. 6, 2005, pp. 829-859.

Cudworth, Erika. Social Lives with Other Animals: Tales of Sex, Death and Love. Palgrave Macmillan, 2011.

Cudworth, Erika. “Beyond Speciesism: Intersectionality, Critical Sociology and the Human Domination of Other Animals." The Rise of Critical Animal Studies: From the Margins to the Centre. Edited by Nik Taylor and Richard Twine, Routledge, 2014, pp. 19-35.

Cudworth, Erika. "Intersectionality, Species and Social Domination." Anarchism and Animal Liberation: Essays on Complementary Elements of Total Liberation. Edited by Anthony J. Nocella II et al, McFarland \& Company, 2015, pp. 93-107.

Cudworth, Erika and Tracey Jensen. "Puppy Love? Animal Companions in the Media." Critical Animal and Media Studies: Communication for Nonhuman Animal Advocacy. Edited by Núria Almiron et al, Routledge, 2016, pp. 185-201.

Fiddes, Nick. Meat: A Natural Symbol. Routledge, 1991. 
This is a pre-publication author draft. The paper will appear in the fall 2017 issue of ISLE: Interdisciplinary Studies in Literature and Environment

Davis, Karen. "Procrustean Solutions to Animal Identity and Welfare Problems." Critical Theory and Animal Liberation. Edited by John Sanbonmatsu, Rowman and Littlefield, pp. 35-53.

Fitzgerald, Amy J. and Nik Taylor. “The Cultural Hegemony of Meat and the Animal Industrial Complex." The Rise of Critical Animal Studies: From the Margins to the Centre. Edited by Nik Taylor and Richard Twine, Routledge, 2014, pp. 165-182.

Fox, Michael Allen. “Vegetarianism and Planetary Health.” Ethics and the Environment, vol. 5, no. 2, 2000, pp. 163-174.

Freeman, Carrie P. “This Little Piggy Went to Press: The American News Media's Construction of Animals in Agriculture." Critical Animal and Media Studies: Communication for Nonhuman Animal Advocacy. Edited by Núria Almiron et al, Routledge, 2016, pp. 169-184.

Jenkins, Stephanie and Richard Twine. “On the limits of food autonomy—rethinking choice and privacy." The Rise of Critical Animal Studies: From the Margins to the Centre. Edited by Nik Taylor and Richard Twine, Routledge, 2014, pp. 225-240.

Linné, Tobias. “Cows on Facebook and Instagram: Interspecies Intimacy in the Social Media Spaces of the Swedish Dairy Industry." Television and New Media, vol. 17, no. 8, 2016, pp. 719-733.

Linné, Tobias and Helena Pedersen. “With Care for Cows and a Love for Milk: Affect and Performance in Swedish Dairy Industry Marketing Strategies." Meat Culture. Edited by Annie Potts, Brill, 2016, pp. 109-128.

Loy, Loredana. “Media Activism and Animal Advocacy: What's Film Got to Do with It?" Critical Animal and Media Studies: Communication for Nonhuman Animal Advocacy. Edited by Núria Almiron et al, Routledge, 2016, pp. 221-233.

Malamud, Randy. "Looking at Humans Looking at Animals." Critical Animal and Media Studies: Communication for Nonhuman Animal Advocacy. Edited by Núria Almiron, Routledge, 2016, pp. 154-168.

Molloy, Claire. Popular Media and Animals. Palgrave Macmillan, 2011. 
This is a pre-publication author draft. The paper will appear in the fall 2017 issue of ISLE: Interdisciplinary Studies in Literature and Environment

Nibert, David. Animal Oppression and Human Violence: Domesecration, Capitalism and Global Conflict. Columbia UP, 2013.

Noske, Barbara. Human and Other Animals. Pluto Press, 1989.

Potts, Annie and Jovian Parry. “Vegan Sexuality: Challenging Heteronormative Masculinity through Meat-free Sex." Feminism \& Psychology, vol. 20 no. 1, 2010, pp. 53-72.

Puss in Boots. Directed by Chris Miller. Paramount, 2011. Film.

Rich, Adrienne. “Compulsory heterosexuality and lesbian existence." Signs: Journal of Women in Culture and Society, vol. 5 no. 4, 1980, pp. 631-660.

Sausage Party. Directed by Greg Tiernan and Conrad Vernon. Columbia, 2016. Film.

“Sausage Party.” Box Office Mojo . IMDb., n.d. Accessed 30 Dec. 2016.

<http:/ / www.boxofficemojo.com/ movies / ?id=sausageparty.htm>.

Shaun the Sheep. Directed by Mark Burton and Richard Starzak. Lionsgate, 2015. Film.

Smith, Mick. "The "ethical" space of the abattoir: on the (in)human(e) slaughter of other animals." Human Ecology Review, vol. 9 no. 2, 2002, pp. 49-58.

Stănescu, Vasile. “The Whopper Virgins: Hamburgers, Gender, and Xenophobia in Burger King's Hamburger Advertising." Meat Culture. Edited Annie Potts, Brill, 2016, pp. 90108.

Stewart, Kate and Matthew Cole. "The Conceptual Separation of Food and Animals in Childhood." Food, Culture and Society, vol. 12, no. 4, 2009, pp. 457-476.

The Lion King. Directed by Roger Allers and Rob Minkoff. Disney, 1994. Film.

Toy Story. Directed by John Lasseter. Buena Vista, 1995. Film.

Twine, Richard. Animals as Biotechnology: Ethics, Sustainability and Critical Animal Studies. Earthscan, 2010.

Twine, Richard. "Revealing the "Animal-Industrial Complex" - A Concept \& Method for Critical Animal Studies?" Journal for Critical Animal Studies, vol. 10, no. 1, 2012, pp. $12-39$.

"UN urges people to eat insects to fight world hunger." BBC News. BBC, 13 May 2013.

Accessed 27 Jan. 2017. < http:/ / www.bbc.co.uk/ news/ world-22508439> 
This is a pre-publication author draft. The paper will appear in the fall 2017 issue of ISLE: Interdisciplinary Studies in Literature and Environment

Weaver, Simon. The Rhetoric of Racist Humour: US, UK and Global Race Joking. Ashgate, 2011.

Wrenn, Corey. A Rational Approach to Human Rights: Extensions in Abolitionist Theory.

Palgrave Macmillan, 2016.

Wright, Laura. The Vegan Studies Project: Food, Animals and Gender in the Age of Terror. U of Georgia P, 2015.

\footnotetext{
${ }^{1}$ See Wrenn (2015) for a fuller discussion of veganism as a social movement.

${ }^{2}$ The decapitation scene occurs in the drug-user's kitchen: he attempts to put Barry in a pan of boiling water, but drops him (at this point not being drugged and therefore unaware of Barry's sentience). When stopping to retrieve Barry, he knocks the pan of water, which spills over him. As he flails in pain, Barry pulls on his shoelace, which causes him to slip and fall. The impact dislodges an axe that happens to be mounted on the wall above. The axe falls and severs his head, enabling Barry to survive.

${ }^{3}$ The term animal-industrial complex was initially coined by Barbara Noske (1989), and later defined by Richard Twine (2012: 24) as "a partly opaque and multiple set of networks and relationships between the corporate (agricultural) sector, governments, and public and private science. With economic, cultural, social and affective dimensions it encompasses an extensive range of practices, technologies, images, identities and markets."
} 